\title{
Multi-period Productivity Measurement under Centralized Management with an Empirical Illustration to German Saving Banks
}

\author{
Mohsen Afsharian*, Heinz Ahn \\ Department of Business Sciences, Technische Universität Braunschweig, Fallersleber-Tor-Wall 23, 38100 \\ Braunschweig, Germany \\ *Corresponding author; Phone:+495313913606; Fax:+495313918121E-mail:m.afsharian@tu-bs.de
}

\begin{abstract}
In this paper, we revisit the structure of the centralized Malmquist indices which apply inter-temporal benchmark technologies coupled with a relaxed assumption that the technology remains unchanged between the start and the end of the analysis. From a theoretical point of view as well as with an empirical application to a panel of German savings banks over the time period 2006-2012, we discuss this premise as the technology - which is naturally under the influence of different external and internal conditions - can change over time. This may hence result in an inappropriate estimate of the benchmark technology, generate questionable sets of commonweights and lead accordingly to misleading results and managerial conclusions. In order to eliminate this pitfall, we propose a new centralized framework in which individual characteristics of the technology, represented by different contemporaneous technology sets over time, can be preserved and later traced in measuring productivity change. Details of our empirical results, determined by the proposed Malmquist index, reveal that the productivity of the group of German savings banks has always been increasing during the whole period analyzed. The positive rates of growth highlight the fact that this group had a stable financial system even when the financial crisis hit the international monetary and financial market. The best practice change component of the suggested Malmquist index also verifies the significant effect of change in the technology on the performance of these banks over time. Although the group of German savings banks reduced its fixed assets over time, our analysis of productivity change shows how successfully these banks could improve even in a highly customized and growing digital business environment. However, looking at the slowdown in the growth of productivity between 2011-2012, captured by our results, it seems advisable that they accelerate the adaptation of their business strategy, e.g. by investing more in high quality and diverse internet-based products and services to catch up with the rapid developments in information technologies.
\end{abstract}

Keywords: Data Envelopment Analysis; Productivity measurement; Centralized management; Common weights; Banking 


\section{Introduction}

In many real world applications of data envelopment analysis (DEA) models, there are situations in which decision making units (DMUs) fall under the umbrella of a centralized management that oversees them. Examples of such centrally managed multi-unit organisations are a bank managing its branches, a tax authority managing local tax offices, a supermarket chain managing its outlets etc. In such cases, the central decision maker of the organization often applies a common set of preferences to improve the overall performance of the whole system. In this context, commonweights DEA models have been shown to be useful not only to measure performance in a static framework, but also where a multi-period analysis, by means of Malmquist indices, is taken into account. A more thorough review of DEA models under centralized management can be found in, e.g., Mar-Molinero et al. (2014) for a static framework and, e.g., in Kao (2010) for a multi-period analysis.

Among the different frameworks to measure productivity over time, the global form of the Malmquist index has recently begun to receive considerable attention by researchers (see, e.g., Portela and Thanassoulis 2008; Oh 2010; Wang et al. 2012). The reason is that this framework applies only a single global benchmark technology which leads the index to generate a single value of productivity change, possess the circularity property and avoid infeasibility issues. It also allows comparing the productivity of DMUs not only within the contemporaneous technologies, but also relative to the potential global benchmark technology available to the industry as a whole. This index was originally proposed by Pastor and Lovell (2005) in the context of a decentralized management scenario. Recently, their framework has been modified to be used under centralized management by Kao (2010). The author applied common-weights DEA models within a certain framework for determining the global Malmquist index and showed that his proposed approach not only retains the above-outlined attractive features, but also produces reliable results for the case of a centralized management.

The global Malmquist index of Kao (2010) under centralized management uses convex combinations of all observations in all time periods to estimate a single global best practice technology. Such an estimate is however based on the "relaxed assumption" that the technology remains unchanged between the start and the end of the analysis. It is assumed to be no technical differences between different DMUs which are observed over time. Accordingly, we have to accept that not only the external environment, such as government rules and regulations as well as the economic condition, remains unaltered over the time periods, but also the internal environment such as the organizational strategies, internal rules and regulations and policy directives. This is clearly a strong premise in real applications as the technology - which is naturally under the influence of 
different external and internal conditions - is likely to change over time. As a consequence, including all convex combinations of all observations in all time periods with different technologies in the analysis is questionable. This issue becomes more problematic when the change in the technology is rapid and observations from different periods have only little in common.

Other sources of this pitfall can be seen in studies which apply so-called inter-temporal benchmark technologies in the structure of the Malmquist index. In these studies, a convex union of some contemporaneous technologies is taken into account. For example, the sequential Malmquist index proposed by Shestalova (2003) applies a benchmark technology which is formed from convex combinations of all observations in all periods up to the period under consideration. Another example is the biennial Malmquist index by Pastor et al. (2011). The authors suggest a biennial benchmark technology, which is defined as the convex combination of observations of the two adjacent time periods under consideration. With same reasons given above for the global Malmquist index, we can argue that the way the benchmark technology is estimated - and accordingly the results of the productivity over time - can be far away from a reasonable approximation of the real system under evaluation.

Against this background, as a starting point, we revisit the structure of the centralized global Malmquist index of Kao (2010) in the following section. In Section 3, we first introduce a new centralized Malmquist index. It will be shown that individual characteristics of the technology, represented by different contemporaneous technologies over time, can be preserved by our approach and later traced in measuring productivity change. The core idea of the proposed centralized Malmquist index is then extended to other existing frameworks of the Malmquist index which apply inter-temporal benchmark technology sets. Furthermore, a matrix of centralized distance functions is derived which can provide additional managerial outcomes for further analyzing productivity. In Section 4, the proposed approach and the corresponding commonweights DEA models will be illustrated by means of an empirical application to a panel of German savings banks. The paper concludes in Section 5 with a summary and an outlook on future research opportunities.

\section{Centralized Standard and Global Malmquist Indices}

\subsection{Notation and Settings}

Suppose that there exist $n$ DMUs in $t(t=1, \ldots, T)$ time periods. Let $X_{j}^{t}=\left(x_{1 j}^{t}, x_{2 j}^{t}, \ldots, x_{m j}^{t}\right) \in \mathfrak{R}_{+}^{m}$ and $Y_{j}^{t}=\left(y_{1 j}^{t}, y_{2 j}^{t}, \ldots, y_{s j}^{t}\right) \in \mathfrak{R}_{+}^{s}$ be non-zero vectors which quantify the level of inputs and outputs of $\mathrm{DMU}_{j}$ in period $t$. In the case of decentralized management, DMUs are assumed to operate 
independently and according to its own priorities only, while under centralized management, the DMUs are supervised by a central decision maker. All DMUs in each time period $t$ are supposed to operate under the same technology, e.g., resulting from the same environment such as government rules and regulations, and the economic condition. For the case of the centralized management, we further assume that not only the above conditions (which are now considered as external environment factors for the group of DMUs), but also the internal environment such as organizational strategies, internal rules and regulations and policy directives remain unaltered between the start and the end of each period $t$. Hence, each contemporaneous technology in time period $t$ can be represented by a production possibility set (PPS) or technology set (in the following also abbreviated as "contemporaneous technology") of feasible input-output combinations as follows:

$$
T^{t}=\left\{(X, Y) \in \mathfrak{R}_{+}^{m} \times \mathfrak{R}_{+}^{s} \mid(X, Y) \text { can be feasible in period } t\right\} .
$$

In terms of properties satisfied by each period $t$, the corresponding contemporaneous technology can be characterized precisely by applying desired mathematical axioms such as non-emptiness, free disposability, ray unboundedness (constant returns to scale - CRS) and convexity (see, e.g., Banker et al. 1984). Throughout the paper, without loss of generality (following, e.g., Färe et al. 1992; Grifell-Tatjé and Lovell 1995; Pastor and Lovell 2005; Kao 2010), we also assume that contemporaneous technologies satisfy these standard axioms. The following analysis may be straightforwardly extended to other types of technologies with different axioms.

\subsection{Decentralized and Centralized Standard Malmquist Index}

On the basis of the above setting, the standard Malmquist index of Färe et al. (1992) for $\mathrm{DMU}_{p}$ $(p=1, \ldots, n)$ between two time periods $t$ and $t+1$ is defined as

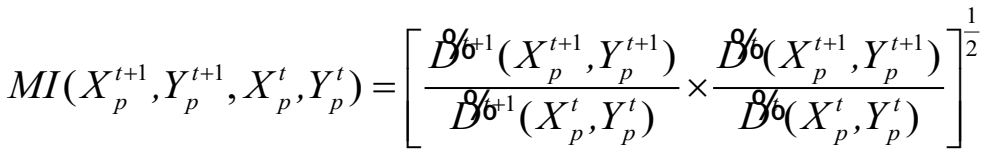

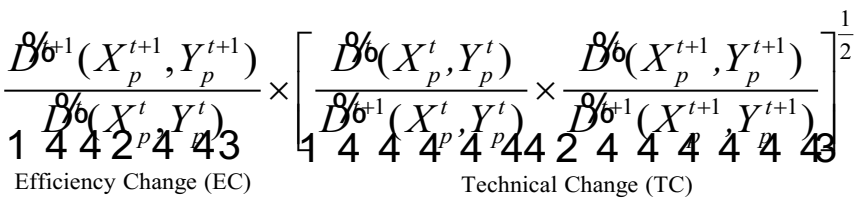

where it has also been exhibited by the multiplication of the efficiency change and technical change components (for a more detailed review of the standard Malmquist index and its decompositions, see Färe et al. 1992). The contemporaneous distance functions $B^{\circ / 6}\left(X_{p}^{l}, Y_{p}^{l}\right), k, l=t, t+1$ in (2) represent the efficiency scores of $\operatorname{DMU}_{p}(p=1, \ldots, n)$ observed in period $l(l=t, t+1)$ against the 
contemporaneous technology $T^{K}(k=t, t+1)$. These distance functions can be determined by means of the standard decentralized DEA model (CCR-DEA model) of Charnes et al. (1978) as

$$
\begin{aligned}
B^{6}\left(X_{p}^{l}, Y_{p}^{l}\right)=\max \left\{\begin{array}{ll}
\sum_{r=1}^{s} u_{r p}^{k l} y_{r p}^{l} \mid \sum_{i=1}^{m} v_{i p}^{k l} x_{i p}^{l}=1, & \\
& \sum_{r=1}^{s} u_{r p}^{k l} y_{r j}^{k}-\sum_{i=1}^{m} v_{i p}^{k l} x_{i j}^{k} \leq 0, \quad j=1, \ldots, n ; \\
& v_{i p}^{k l} \geq \varepsilon, \quad i=1, \ldots, m ; u_{r p}^{k l} \geq \varepsilon, \quad r=1, \ldots, s
\end{array}\right\}
\end{aligned}
$$

where $\left(u_{r p}^{k l}, v_{i p}^{k l}\right)$ stands for the weights (multipliers) of outputs and inputs respectively and $\varepsilon$ is the non-Archimedean infinitesimal Epsilon which is used to prevent any input or output to be ignored from the analysis (for more details see, e.g., Mehrabian et al. 2000). While model (3) is based on input distance functions, the definition of output distance functions can be done similarly.

More recently, Kao and Hung (2005) introduced a two-stage compromise solution approach to determine a set of input-output weights which can be used for measuring the efficiency of all DMUs on a same basis (see also Zohrehbandian et al. 2010). In the first stage, the decentralized DEA model in (3) is applied to compute the efficiency score of each DMU observed in period $l$ against to the contemporaneous technology $T^{K}$. As the model is a decentralized one, the efficiency scores are determined from the most favorable multipliers which presents the so-called ideal efficiency scores that the DMUs can reach, i.e. any other set of multipliers can only produce smaller efficiency scores. In the second stage, a common set of weights can be determined by minimizing the total squared difference between the ideal efficiency scores and that obtained from the common weights of each DMU as

$$
\begin{aligned}
& C W^{k}\left(X_{j}^{l}, Y_{j}^{l}: \forall j\right)=\min \left\{\sum_{j=1}^{n}\left(B^{6}\left(X_{j}^{l}, Y_{j}^{l}\right)-\sum_{r=1}^{s} u_{r}^{k l} y_{r j}^{l} / \sum_{i=1}^{m} v_{i}^{k l} x_{i j}^{l}\right)^{2} \mid\right. \\
& \left.\begin{array}{ll}
\sum_{r=1}^{s} u_{r}^{k l} y_{r j}^{k}-\sum_{i=1}^{m} v_{i}^{k l} x_{i j}^{k} \leq 0, & j=1, \ldots, n ; \\
v_{i}^{k l} \geq \varepsilon, \quad i=1, \ldots, m ; u_{r}^{k l} \geq \varepsilon, & r=1, \ldots, s
\end{array}\right\}
\end{aligned}
$$

where $B^{6}\left(X_{j}^{l}, Y_{j}^{l}\right), k, l=t, t+1$ represent ideal efficiency scores which are calculated in advance by (3). The notation used for $C W^{k}\left(X_{j}^{l}, Y_{j}^{l}: \forall j\right)$ in (4) highlights the fact that the common set of weights, shown by $\left(u_{r}^{k l^{*}}, v_{i}^{k l^{*}}\right)$, is determined for all DMUs $(j=1, \ldots, n)$ observed in period $l$ with respect to the contemporaneous technology $T^{K}$. After having computed this set of weights, the common-weights efficiency score of each $\operatorname{DMU}_{p}(p=1, \ldots, n)$ can be determined by the ratio 


$$
B_{C M}^{6}\left(X_{p}^{l}, Y_{p}^{l}\right)=\frac{\sum_{r=1}^{s} u_{r}^{k l^{*}} y_{r p}^{l}}{\sum_{i=1}^{m} v_{i}^{k l^{*}} x_{i p}^{l}} \quad k, l=t, t+1
$$

where the results have also been denoted by a subscript " $C M$ " to emphasize that the distance functions are now computed under centralized management and based on the common-weights DEA model in (4). The Malmquist index in (2) can now be measured under centralized management by means of these centralized contemporaneous distances functions.

\subsection{Decentralized and Centralized Global Malmquist Index}

According to Pastor and Lovell (2005) and Kao (2010), the global Malmquist index uses the global production possibility set or global technology which is the set including all data of observations from all periods:

$$
T^{G}=\left\{(X, Y) \in \mathfrak{R}_{+}^{m} \times \mathfrak{R}_{+}^{s} \mid(X, Y) \text { can be feasible in all periods }\right\} .
$$

Compared to the standard Malmquist index in (2), since there is only a single (global) best practice technology, there is no need to resort to the geometric mean convention when defining the global form of the Malmquist index. Hence, the global Malmquist index is determined as

$$
\begin{aligned}
& G M I\left(X_{p}^{t+1}, Y_{p}^{t+1}, X_{p}^{t}, Y_{p}^{t}\right)=\frac{B^{6}\left(X_{p}^{t+1}, Y_{p}^{t+1}\right)}{B^{6}\left(X_{p}^{t}, Y_{p}^{t}\right)}
\end{aligned}
$$

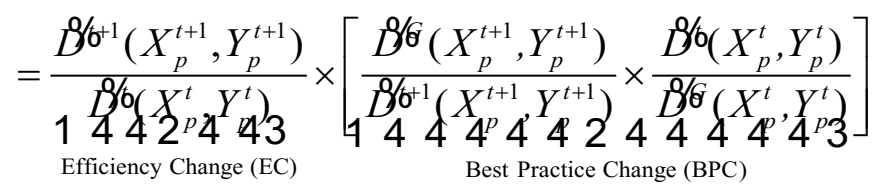

whose result has been represented by the multiplication of the efficiency change and best practice change components (for a detailed review of the global Malmquist index and its decompositions, see Pastor and Lovell 2005). Under decentralized management, $B^{6}\left(X_{p}^{l}, Y_{p}^{l}\right), k, l=t, t+1$ in (7) can be computed by (3), while the global distance functions $B^{8}\left(X_{p}^{l}, Y_{p}^{l}\right), l=t, t+1$ can be determined as

$$
\left.\begin{array}{rl}
B^{G}\left(X_{p}^{l}, Y_{p}^{l}\right)=\max & \left\{\sum_{r=1}^{s} u_{r p}^{G l} y_{r p}^{l} \mid \sum_{i=1}^{m} v_{i p}^{G l} x_{i p}^{l}=1,\right. \\
& \sum_{r=1}^{s} u_{r p}^{G l} y_{r j}^{k}-\sum_{i=1}^{m} v_{i p}^{G l} x_{i j}^{k} \leq 0, \quad j=1, \ldots, n ; k=1, \ldots, T \\
& v_{i p}^{G l} \geq \varepsilon, \quad i=1, \ldots, m ; \quad u_{r p}^{G l} \geq \varepsilon, \quad r=1, \ldots, s .
\end{array}\right\}
$$


This model has the same structure as (3), but it applies the global benchmark technology, which includes all observations from all periods. Hence, the model can be considered as an extension of the decentralized model in (3), which provides individual multipliers for the DMUs observed in period $l$ against the global technology, i.e. $\left(u_{r j}^{G l^{*}}, v_{i j}^{G *^{*}}\right), j=1, \ldots, n$. Similar to (4), a common set of weights to measure efficiency under centralized management can also be determined by

$$
\left.\begin{array}{rl}
C W^{G}\left(X_{j}^{k}, Y_{j}^{k}: \forall j, \forall k\right)=\min & \left\{\sum_{k=1}^{T} \sum_{j=1}^{n}\left(B^{G}\left(X_{j}^{k}, Y_{j}^{k}\right)-\sum_{r=1}^{s} u_{r}^{G} y_{r j}^{k} / \sum_{i=1}^{m} v_{i}^{G} x_{i j}^{k}\right)^{2} \mid\right. \\
& \left.\sum_{r=1}^{s} u_{r}^{G} y_{r j}^{k}-\sum_{i=1}^{m} v_{i}^{G} x_{i j}^{k} \leq 0, \quad j=1, \ldots, n ; k=1, \ldots, T\right\} \\
v_{i}^{G} \geq \varepsilon, \quad i=1, \ldots, m ; u_{r}^{G} \geq \varepsilon, \quad r=1, \ldots, s
\end{array}\right\}
$$

where $B^{6}\left(X_{j}^{k}, Y_{j}^{k}\right), \quad k=1, \ldots, T$ represent ideal efficiency scores according to the global benchmark technology which can be calculated in advance by (8). $C W^{G}\left(X_{j}^{k}, Y_{j}^{k}: \forall j, \forall k\right)$ in (9) shows that a single common set of weights is determined for all $n$ DMUs $(j=1, \ldots, n)$ observed in all $T(k=1, \ldots, T)$ periods by making use of the global benchmark technology $T^{G}$. After this single set of weights $\left(u_{r}^{G^{*}}, v_{i}^{G^{*}}\right)$ is obtained, the common-weights efficiency score of each $\operatorname{DMU}_{p}(p=1, \ldots, n)$ can be determined by the following ratio:

$$
B_{C M}^{G}\left(X_{p}^{l}, Y_{p}^{l}\right)=\frac{\sum_{r=1}^{s} u_{r}^{G^{*}} y_{r p}^{l}}{\sum_{i=1}^{m} v_{i}^{G^{*}} x_{i p}^{l}} \quad l=t, t+1
$$

The global Malmquist index in (7) can now be measured under centralized management by means of the distances functions in (5) and (10).

\section{A New Centralized Malmquist Index}

\subsection{Motivation}

Consider a centralized management scenario such as the one outlined in the previous section where there exist $n$ DMUs observed in $T$ time periods. It should be emphasized once again that DMUs in each time period are assumed to operate under the same technology resulting from the same internal and external environment. We further assume that each contemporaneous technology remains unaltered between the start and the end of each time period $t$. On this basis, we accept that not only the external environment, such as government rules and regulations as well as the economic 
condition, can change over the time periods, but also the internal environment such as the organizational strategies, internal rules and regulations and policy directives.

In the global form of the Malmquist index, by definition, all observations from all periods are assumed to be theoretically and potentially able to access a single best practice technology, i.e. the global benchmark technology available to the industry as a whole. This benchmark technology is obtained by the convex aggregation of the experienced contemporaneous technologies (see also Oh and Lee 2010; Chen and Yang 2011). Accordingly, in order to measure the global Malmquist index under centralized management in (7), models (8) and (9) are used which have the same structure as models (3) and (4), respectively. Unlike in models (3) and (4), which use observations form a single period, models (8) and (9) (as their extended mathematical models) apply all observations from all periods. This clarifies the fact that the same assumptions (i.e. non-emptiness, free disposability, convexity and ray unboundedness), which are used for each contemporaneous technology, are also applied intact to the set of all observations from all periods in measuring the global distance functions.

Accordingly, all observations from different time periods are accepted to form the global benchmark technology under centralized management. This means that the characteristics of the technology are implicitly assumed to remain unaltered over time, i.e. it is assumed to be no technical differences between different groups of DMUs which are observed over time. This is clearly inconsistent with the pre-assumption that the technology is only supposed to be constant between the start and the end of each time period, but it may change over time. It should be noted (as it was also supposed as a pre-assumption in advance) that under central management, the internal and external environment in which DMUs operate can change over time. As a consequence, although observations in each time period can be considered to be acceptable to form the respective contemporaneous technology set, including all observations from all periods with different technologies in the analysis (to estimate the global benchmark technology) is questionable.

This kind of forming the best practice technology may mathematically produce virtual units which are created by convex combinations of DMUs from distinct technologies. The reason is that models (8) and (9) consider all DMUs in the analysis "homogeneous" and their convex combinations "feasible". Hence, the corresponding common set of input-output weights computed by (9) can be determined on the basis of the existence of virtual units which have neither been experienced over time nor may not be producible in reality. As a consequence, the estimated productivity changes in (7), determined on the basis of this type of the best practice technology, may become unreliable. 
A graphical example of this can be seen in Figure 1 which depicts a global benchmark technology formed from observations in three time periods with two inputs and a single output. The contemporaneous technologies $T^{1}, T^{2}, T^{3}$ are the areas bounded by ABCD, EFGH and IJKL, respectively. On this basis, the global technology is the area bounded by ABFGKL. Considering the efficient frontier of the global technology set, we can see that the segment BF is constructed by a convex combination of units $\mathrm{B}$ and $\mathrm{F}$ which are originated from different contemporaneous technologies, i.e. technologies $T^{1}$ and $T^{2}$. The same applies to the segment GK whose exterior points $\mathrm{G}$ and $\mathrm{K}$ come from technologies $T^{2}$ and $T^{3}$. That is the result of the assumption that all observations from different time periods are considered to be homogeneous so that their convex combinations are accepted to be feasible. A direct consequence of this assumption also adds areas to the global technology which are only formed when convexity is applied between observations from the three time periods. In our case, these areas are represented by triangles BMF and GNK.

Figure. 1 The global benchmark technology.

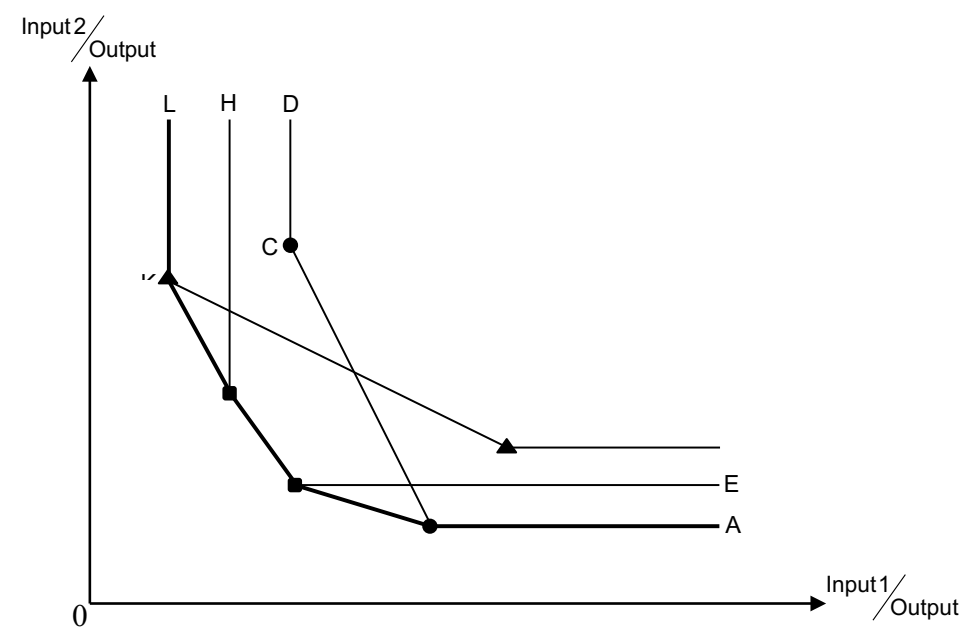

Assuming convexity even between observations within each contemporaneous period is a strong premise, while there are distinct technologies which may be affected by a different internal and external environment under centralized management. Therefore, even if contemporaneous technology sets satisfy convexity (resulting from the same environment in each time period), as the environment can change over time there is no reason why the union of these technology sets should be convex. This phenomenon becomes more problematic when the change in the technology is rapid and observations from different periods have little or nothing in common. Then, such a global production possibility set is not an appropriate estimate of the best practice technology as a single benchmark technology which has really been experienced over time. Accordingly, an alternative union of the contemporaneous technologies is needed, which can avoid producing inappropriate virtual units in the global benchmark technology. Under centralized management, such an 
alternative can be developed on the basis of the overall benchmark technology proposed by Afsharian and Ahn (2014) in the context of a decentralized management scenario. In the next section, after the overall benchmark technology under centralized management is defined, the proposed centralized distance functions and the corresponding centralized Malmquist index are addressed.

\subsection{The Centralized Distance Functions}

Under the above described centralized management, an alternative union of the contemporaneous technologies can be determined by applying the minimum extrapolation principle on the union of what has really been experienced over time. This is mathematically done by means of a safe definition which does not necessitate any further assumptions to be made for the union of the experienced technologies

$$
T^{O}=T^{1} \cup \ldots \cup T^{T}
$$

where $T^{O}$ (i.e. the overall benchmark technology) is a pure union of the experienced contemporaneous technologies. In Figure 2, the overall benchmark technology of the three contemporaneous technologies is the area bounded by ABMFGNKL.

Figure. 2 The overall benchmark technology.

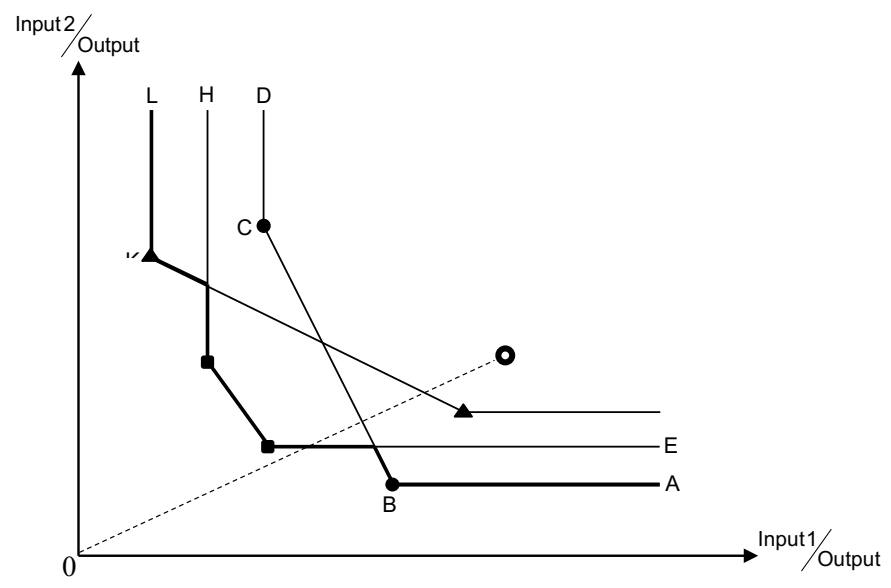

By means of definition (11), as can also been seen in Figure 2, observations in each time period are still assumed to be homogeneous to form the respective contemporaneous technology set. Hence, it is accepted that the technology remains constant between the start and end of each time period. However, because of possible changes in the characteristics of the technology over time, convex combinations of observations from different time periods is not permitted to form the overall benchmark technology. With respect to the definition of the overall benchmark technology in (11), overall distance functions $B^{\ell / 8}\left(X_{p}^{l}, Y_{p}^{l}\right), l=t, t+1$ can be determined by means of an enumeration-based procedure as follows: 


$$
\begin{aligned}
& B^{\beta}\left(X_{p}^{l}, Y_{p}^{l}\right)=\min \left\{B^{b}\left(X_{p}^{l}, Y_{p}^{l}\right), \ldots, B^{b}\left(X_{p}^{l}, Y_{p}^{l}\right)\right\}= \\
& \min \left\{\max \left\{\begin{array}{l|l}
\sum_{r=1}^{s} u_{r}^{k l} y_{r p}^{l} & \begin{array}{l}
\sum_{i=1}^{m} v_{i}^{k l} x_{i p}^{l}=1, \\
\sum_{r=1}^{s} u_{r}^{k l} y_{r j}^{k}-\sum_{i=1}^{m} v_{i}^{k l} x_{i j}^{k} \leq 0, \\
v_{i}^{k l} \geq \varepsilon, \quad i=1, \ldots, m ;
\end{array} \quad u_{r}^{k l} \geq \varepsilon, \quad r=1, \ldots, s .
\end{array}\right\}, k=1, \ldots, T\right\}
\end{aligned}
$$

In this model, determining $B^{8}\left(X_{p}^{l}, Y_{p}^{l}\right), l=t, t+1$ according to the overall benchmark technology is identical with finding the minimum value among $\left\{B^{\mathscr{b}}\left(X_{p}^{l}, Y_{p}^{l}\right), B^{\natural} \hat{\emptyset}\left(X_{p}^{l}, Y_{p}^{l}\right), \ldots, B^{\widehat{\delta}}\left(X_{p}^{l}, Y_{p}^{l}\right)\right\}$ in which $B^{6 / 6}\left(X_{p}^{l}, Y_{p}^{l}\right),(k=1, \ldots, T)$ could also be computed in advance by model (3). Thus, there exists $k, k \in\{1, \ldots T\}$, such that $B^{8}\left(X^{l}, Y^{l}\right)=B^{6}\left(X^{l}, Y^{l}\right)$. As an example, let us determine $B^{\beta}(U)$ which represents the overall distance function for a unit " $U$ " in connection with Figure 2 . According to the enumeration procedure, the results will be the minimum value among the three contemporaneous distance functions $\left\{B^{\mathscr{b}}(U), B^{\hat{⿵}}(U), B^{\hat{o}}(U)\right\}$. Setting appropriate periods of time in (3), these distance functions can be computed as $\left\{O U_{1} / O U, O U_{2} / O U, O U_{3} / O U\right\}$. As the minimum value occurs in connection to the benchmark technology $T^{2}$, therefore $B^{8 / 8}(U)=B^{8}(U)=O U_{2} / O U$.

In global distance functions which are computed by (8), individual weights $\left(u_{r p}^{G l^{*}}, v_{i p}^{G l^{*}}\right)$ for a $\mathrm{DMU}_{p}$ under evaluation are determined by considering all observations from all periods. Therefore, these weights might be obtained on the basis of convex combinations of observations which originate from periods with significant technological differences. In contrast to that, as can be seen in (12), overall distance functions provide input-output weights which are determined by observations only from the same contemporaneous technology, i.e. there exists $k, k \in\{1, \ldots T\}$, $\left(u_{r p}^{O l^{*}}, v_{i p}^{O l^{*}}\right)=\left(u_{r p}^{k k^{*}}, v_{i p}^{k k^{*}}\right)$. However, model (12) computes $B^{\beta}\left(X_{p}^{l}, Y_{p}^{l}\right), l=t, t+1 \quad$ under $\quad$ a decentralized management. According to the definition of the overall benchmark technology in (11), these distance functions can now be determined under centralized management by means of an enumeration-based procedure as

$$
\begin{aligned}
\mathscr{B}_{C M}^{8}\left(X_{p}^{l}, Y_{p}^{l}\right) & =\min \left\{B_{C M}^{\complement}\left(X_{p}^{l}, Y_{p}^{l}\right), \ldots, B_{C M}^{\delta}\left(X_{p}^{l}, Y_{p}^{l}\right)\right\} \\
& =\min \left\{\frac{\sum_{r=1}^{s} u_{r}^{1 l^{*}} y_{r p}^{l}}{\sum_{i=1}^{m} v_{i}^{1 l^{*}} x_{i p}^{l}}, \ldots, \frac{\sum_{r=1}^{s} u_{r}^{T l^{*}} y_{r p}^{l}}{\sum_{i=1}^{m} v_{i}^{T l^{*}} x_{i p}^{l}}\right\}
\end{aligned}
$$


In this procedure, determining $B_{C M}^{8}\left(X_{p}^{l}, Y_{p}^{l}\right), l=t, t+1$ against the overall benchmark technology is identical with finding the minimum value among the centralized distance functions $\left\{B_{C M}^{b}\left(X_{p}^{l}, Y_{p}^{l}\right), B_{C M}^{6}\left(X_{p}^{l}, Y_{p}^{l}\right), \ldots, B_{C M}^{6}\left(X_{p}^{l}, Y_{p}^{l}\right)\right\}$ in which $B_{C M}^{6}\left(X_{p}^{l}, Y_{p}^{l}\right),(k=1, \ldots, T)$ could also be computed in advance by the formula in (5). Hence, there exists $k, k \in\{1, \ldots T\}$, such that $B_{C M}^{\otimes}\left(X^{l}, Y^{l}\right)=B_{C M}^{6}\left(X^{l}, Y^{l}\right)$. The global Malmquist index in (7) can now be modified to be applied in a centralized management scenario by means of proposed distances functions in (5) and (13) as follows:

$$
\begin{aligned}
& \operatorname{OMI}\left(X_{p}^{t+1}, Y_{p}^{t+1}, X_{p}^{t}, Y_{p}^{t}\right)=\frac{B_{C M}^{8}\left(X_{p}^{t+1}, Y_{p}^{t+1}\right)}{B_{C M}^{8}\left(X_{p}^{t}, Y_{p}^{t}\right)}
\end{aligned}
$$

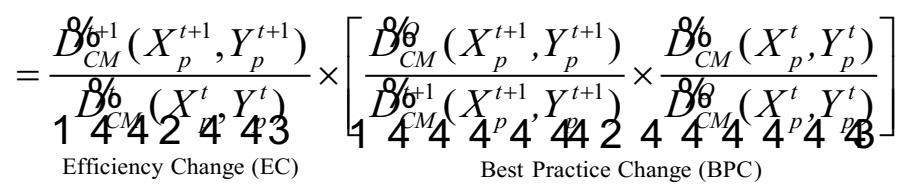

Taking a closer look at model (10), introduced by Kao (2010), it can be seen that the common set of weights $\left(u_{r}^{G^{*}}, v_{i}^{G^{*}}\right)$ in the respective global form of the Malmquist index is computed by a single mathematical model including all observations in all periods, i.e. $C M^{G}\left(X_{j}^{k}, Y_{j}^{k}: \forall j, \forall k\right)$. Hence, the obtained common set of weights does not distinguish between observations which are originated from different contemporaneous technologies. As a consequence, the common-weights efficiency scores of DMUs observed in any period of time is measured by a single common set of weights. This once again highlights the fact that in this global form of the Malmquist index, such an outlined non-homogeneity problem is not taken into account when determining the common set of weights.

Now let us denote the common set of weights associated to $B_{C M}^{8}\left(X^{l}, Y^{l}\right)$ by $C W^{o}\left(X_{j}^{l}, Y_{j}^{l}: \forall j\right)$. According to the proposed model in (13), for each group of DMUs observed in period $l$, which operate under the same contemporaneous technology, a common set of weights is determined, i.e. $\left(u_{r}^{O l^{*}}, v_{i}^{O l^{*}}\right)$. This reveals that this model avoids mixing observations from periods with technological differences in determining common sets of weights. Therefore, it allows creating a benchmark technology set which provides an acceptable level of discrimination between nonhomogeneous observations in its estimate. This mathematical feature of the proposed model also plays a crucial role in measuring performance under centralized management. The reason is that the corresponding Malmquist index preserves the central decision maker's preferences which are imposed over time to form the benchmarking technology. In other words, individual characteristics of the technology, represented by different contemporaneous technologies over time, can be 
preserved and traced in measuring the overall distance functions. This feature also provides additional computational advantages which will be investigated in the next section.

\subsection{Matrix of Centralized Distance Functions}

In order to measure the overall Malmquist index in (14) for a unit $p$ between two time periods $t$ and $t+1$, the proposed overall distance functions $B_{C M}^{8}\left(X_{p}^{t}, Y_{p}^{t}\right)$ and $B_{C M}^{8}\left(X_{p}^{t+1}, Y_{p}^{t+1}\right)$ have to be computed. Therefore, if there exists a panel of $T(k=1, \ldots, T)$ contemporaneous technologies in the analysis, $T$ overall distance functions $B_{C M}^{\otimes}\left(X_{p}^{1}, Y_{p}^{1}\right), \ldots, B_{C M}^{\otimes}\left(X_{p}^{T}, Y_{p}^{T}\right)$ need to be determined by the enumeration procedure in (13) to measure the overall Malmquist index for this unit in all these periods. This requires the following set of contemporaneous distance functions to be solved in advance to be included in the enumeration procedure:

\begin{tabular}{|c|c|c|c|c|c|c|c|}
\hline & $T^{1}$ & $\mathrm{~K}$ & $T^{t-1}$ & $T^{t}$ & $T^{t+1}$ & $\mathrm{~K}$ & $T^{T}$ \\
\hline$U_{p}^{1}$ & $B_{C M}^{b}\left(U_{p}^{1}\right)$ & $\mathrm{K}$ & $B_{C M}^{b^{-1}}\left(U_{p}^{1}\right)$ & $B_{C M}^{6}\left(U_{p}^{1}\right)$ & $B_{C M}^{6+1}\left(U_{p}^{1}\right)$ & $\mathrm{K}$ & $D_{C M}^{6}\left(U_{p}^{1}\right)$ \\
\hline & $\mathrm{M}$ & & $M$ & $\mathrm{M}$ & $\mathrm{M}$ & & M \\
\hline$U_{p}^{t-1}$ & $B_{C M}^{\mathscr{b}}\left(U_{p}^{t-1}\right)$ & $\mathrm{K}$ & $B_{C M}^{6 / b-1}\left(U_{p}^{t-1}\right)$ & $B_{C M}^{6}\left(U_{p}^{t-1}\right)$ & $B_{C M}^{p^{+1}}\left(U_{p}^{t-1}\right)$ & $\mathrm{K}$ & $B_{C M}^{6}\left(U_{p}^{t-1}\right)$ \\
\hline$U_{p}^{t}$ & $B_{C M}^{6}\left(U_{p}^{t}\right)$ & K & $B_{C M}^{6-1}\left(U_{p}^{t}\right)$ & $B_{C M}^{b}\left(U_{p}^{t}\right)$ & $B_{C M}^{\delta^{+1}}\left(U_{p}^{t}\right)$ & K & $B_{C M}^{\delta}\left(U_{p}^{t}\right)$ \\
\hline$U^{t+1}$ & $B_{C M}^{b}\left(U_{p}^{t+1}\right)$ & K & $B_{C M}^{\sigma^{-1}}\left(U_{p}^{t+1}\right)$ & $B_{C M}^{6}\left(U_{p}^{t+1}\right)$ & $B_{C M}^{\delta^{+1}}\left(U_{p}^{t+1}\right)$ & $\mathrm{K}$ & $B_{C M}{ }^{6}\left(U_{p}^{t+1}\right)$ \\
\hline & $\mathrm{M}$ & & $\mathrm{M}$ & $\mathrm{M}$ & $M$ & & $M$ \\
\hline$J J^{T}$ & $B_{C M}^{b}\left(U_{p}^{T}\right)$ & K & $B_{C M}^{\sigma^{-1}}\left(U_{p}^{T}\right)$ & $B_{C M}^{\circ}\left(U_{p}^{T}\right)$ & $B_{C M}^{\delta^{+1}}\left(U_{p}^{T}\right)$ & $K$ & $B_{C M}^{6}\left(U_{p}^{T}\right)$ \\
\hline
\end{tabular}

where, in order to save space, the data of $\mathrm{DMU}_{p}$ in period $k(k=1, \ldots, T)$ has been shown only by $U_{p}^{k}$. As can be seen in this matrix, there are $T$ rows whose values are the efficiency scores of the unit under evaluation observed in period $k(k=1, \ldots, T)$ according to the contemporaneous technology $T^{k}$ $(k=1, \ldots, T)$. Hence, e.g., determining $B_{C M}^{8}\left(X_{p}^{t}, Y_{p}^{t}\right)$ is identical with finding the minimum value among distance functions values in the $t^{\text {th }}$ row, i.e. $\min \left\{B_{C M}^{6}\left(X_{p}^{t}, Y_{p}^{t}\right), \ldots, B_{C M}^{6}\left(X_{p}^{t}, Y_{p}^{t}\right)\right\}$. For the determination of the $E C$ and $B P C$ components of the proposed overall Malmquist index in (14), between adjacent time periods $t$ and $t+1$, e.g., one needs also to solve two additional distance functions $B_{C M}^{6}\left(X_{p}^{t}, Y_{p}^{t}\right)$ and $B_{C M}^{\delta^{+1}}\left(X_{p}^{t+1}, Y_{p}^{t+1}\right)$. However, these additional distances functions have already been computed in the enumeration procedure and are then available in the matrix. This discrete nature of the computational process exists due to the fact that, unlike in the global Malmquist index, the overall Malmquist index does not include all units from all periods in a single global technology. Apart from the conceptual necessity of this structure (see the previous section), the computational process of the proposed index also provides other interesting outcomes described in the following. 
Comparing the definition of the global and overall technologies, we can realize that $T^{O} \subseteq T^{G}$, where $T^{O}=T^{1} \cup \ldots \cup T^{T}$ and $T^{G}=$ Convex $\left\{T^{1} \cup \ldots \cup T^{T}\right\}$. This shows that observations from a new observed technology may add areas to the global technology $T^{G}$, according to the fact that convexity is applied between observations from all periods in this approach (see also Figures 1 and 2). Hence, the estimation of the best practice technology may change significantly when new observations are added to the analysis. Obviously, the proposed (non-convex) estimation of the best practice technology is immune to such extreme changes resulting from new observations added to the estimation of the best practice technology. The straightforward corollary is that - compared to the global Malmquist index - our proposed index will remain less sensitive with respect to changes in the shape of the benchmark technology resulting from new observations. A closer look at the matrix and the enumeration procedure in (13) also implies that the overall Malmquist index and its components do not need to be recomputed completely when a new time period is incorporated. In other words, it allows storing previous results to avoid recalculation and hence only values of distance functions resulting from the new observed technology have to be determined for including into the enumeration procedures.

The computational feature of the proposed framework represented by the above matrix also allows extracting other valuable information in a multi-period productivity analysis. Any vertical analysis in the matrix provides managerial information about the performance of the unit under evaluation with regard to a desired contemporaneous technology. For example, one can measure productivity changes between two adjacent time periods $\mathrm{t}$ and $\mathrm{t}+1$ against a specific contemporaneous technology $T^{k}$. On this basis, a corresponding fixed-period Malmquist index can also be defined as

$$
F M I\left(X_{p}^{t+1}, Y_{p}^{t+1}, X_{p}^{t}, Y_{p}^{t}\right)=\frac{B_{C M}^{6}\left(X_{p}^{t+1}, Y_{p}^{t+1}\right)}{B_{C M}^{6}\left(X_{p}^{t}, Y_{p}^{t}\right)}
$$

This type of the Malmquist index has also been proposed by Berg et al. (1992). The authors suggested applying the special case of $k=1$, which derives their so-called base-period Malmquist index. In our setting, this refers to the vertical analysis in the matrix according to the first contemporaneous technology.

As stated earlier in Section 2, the standard Malmquist index proposed by Färe et al. (1992) applies the geometric mean of two measures of productivity change, which corresponds to the adjacent contemporaneous technologies $T^{t}$ and $T^{t+1}$ under evaluation:

$$
M I\left(X_{p}^{t+1}, Y_{p}^{t+1}, X_{p}^{t}, Y_{p}^{t}\right)=\left[\frac{B_{C M}^{b^{+1}}\left(X_{p}^{t+1}, Y_{p}^{t+1}\right)}{B_{C M}^{b^{+1}}\left(X_{p}^{t}, Y_{p}^{t}\right)} \times \frac{B_{C M}^{6}\left(X_{p}^{t+1}, Y_{p}^{t+1}\right)}{B_{C M}^{6}\left(X_{p}^{t}, Y_{p}^{t}\right)}\right]^{\frac{1}{2}}
$$


As can be seen in (17), four distance functions have to be determined. However, computing the overall Malmquist index, the values of these distance functions are already available in the matrix. On this basis, one can consider the standard Malmquist index of Färe et al. (1992) as an extended vertical analysis outlined above in which two adjacent contemporaneous technologies $T^{t}$ and $T^{t+1}$ are included simultaneously in the measurement.

Pastor et al. (2011) suggested a biennial benchmark technology which is defined as the union of observations of the adjacent time periods under consideration. On this basis, their proposed biennial Malmquist productivity index is determined by the ratio

$$
B M I\left(X_{p}^{t+1}, Y_{p}^{t+1}, X_{p}^{t}, Y_{p}^{t}\right)=\frac{B_{C M}^{B(t, t+1)}\left(X_{p}^{t+1}, Y_{p}^{t+1}\right)}{B_{C M}^{(B t, t+1)}\left(X_{p}^{t}, Y_{p}^{t}\right)}
$$

where the biennial benchmark technology can be formed by $T^{B(t, t+1)}=T^{t} \cup T^{t+1}$. It has to be emphasized that this definition of $T^{B(t, t+1)}$ has already been modified according to our proposed pure union of adjacent contemporaneous technologies $T^{t}$ and $T^{t+1}$. Hence, these distance functions can now be determined by means of already available distance function values in the matrix as $B_{C M}^{B(t, t+1)}\left(X_{p}^{k}, Y_{p}^{k}\right)=\min \left\{B_{C M}^{6}\left(X_{p}^{k}, Y_{p}^{k}\right), B_{C M}^{b^{+1}}\left(X_{p}^{k}, Y_{p}^{k}\right)\right\}, k=t, t+1$. This shows that such an analysis can additionally be done by making use of values in the matrix (15).

In some settings, we may also be interested in running a sequential analysis as proposed first by Shestalova (2003). In this framework, a sequential technology is formed by considering all observations in all periods up to the period under consideration. By applying the proposed pure aggregation of contemporaneous technologies, e.g., the sequential benchmark technology in period $T^{t+1}$ is formed as $T^{S(t+1)}=T^{1} \cup \ldots \cup T^{t+1}$. On this basis, the resulting sequential Malmquist index for the unit under evaluation between two time periods $t$ and $t+1$ can be determined as follows:

$$
\operatorname{SMI}\left(X_{p}^{t+1}, Y_{p}^{t+1}, X_{p}^{t}, Y_{p}^{t}\right)=\frac{B_{C M}^{\delta} \delta_{C M}^{(t+1)}\left(X_{p}^{t+1}, Y_{p}^{t+1}\right)}{B_{C M}^{\delta(t+1)}\left(X_{p}^{t}, Y_{p}^{t}\right)}
$$

These distance functions can be computed by an appropriate setting of (13) in which only distance functions up to period $T^{t+1}$ should be included in the enumeration procedure. However, the required distance functions are already available in rows $t$ and $t+1$ of the matrix. Therefore, they can be determined as $B_{C M}^{\delta} \delta_{c}^{(t+1)}\left(X_{p}^{k}, Y_{p}^{k}\right)=\min \left\{B_{C M}^{b}\left(X_{p}^{k}, Y_{p}^{k}\right), \ldots, B_{C M}^{b^{+1}}\left(X_{p}^{k}, Y_{p}^{k}\right)\right\}, k=t, t+1$. This once again highlights the computational benefits of the proposed framework to also analyze performance under other commonly used forms of the Malmquist index. 


\section{An Empirical Illustration to German Savings Banks}

In order to illustrate how the proposed common-weights overall Malmquist index measures the productivity change over time, we analyze a panel of 417 German savings banks (i.e. $n=417$ DMUs) over the time period 2006-2012 (i.e. $t=2006, \ldots, 2012$ ).

\subsection{The German Savings Banks Sector}

The German banking market comprises mainly universal banks which provide a wide variety of financial services to their customers ranging from individuals to large businesses (Baums and Gruson 1993). These banks are usually classified into three main groups, namely commercial banks, mutual cooperative banks and savings banks (Gischer and Reichling 2010). They are all subject to the German Banking Act and supervised by the German Federal Financial Supervisory Authority (BaFin) and the German Central Bank (Bundesbank). Nevertheless, the three types of banking service providers differ in their ownership structure, business model and guarantee system, competing closely with each other in the market (for more details, see, e.g., Gischer and Reichling 2010).

German savings banks, with a common trade brand Sparkasse, form the heart of the savings banks sector in Germany (Inside the Savings Banks Finance Group 2015). They are essentially credit institutions which operate under a so-called public mandate. Their responsible government departments (but not owners) are the local authorities (e.g., municipalities and regional associations) in the regions a particular saving bank is situated, i.e. local authorities have no shares and cannot sell savings banks. Their obligation is, among others, to provide financial services for all income-level individual customers as well as the small and medium-sized enterprises within their defined geographic business areas. The public mandate also forms the basis for their business model in supporting their municipalities and regional associations in order to facilitate economic development, regional policy and social as well as cultural programs (for further details about the structure of German saving banks, see dsgv's financial report in 2011; Vitols 1995; Simpson 2013).

German savings banks are not a consolidated group with a classic corporate center. They operate independently and are managed in a self-reliant way. Each bank is locally administrated by its own management board which is comprised of banking professionals and qualified members. The management board is responsible for the day-to-day conduct of the business and reporting to a supervisory board of representatives of the customers, employees and the regional association/council. Nevertheless, saving banks are also controlled centrally by the German Savings Banks Association (Deutscher Sparkassen- und Giroverband, DSGV). DSGV is the umbrella organization which is responsible for coordinating decision making within the group, determining strategic directions, making general policy decisions and monitoring the activities of the banks to ensure effective and efficient operation with low risk (see dsgv.de; Simpson 2013). 
Under these circumstances, DSGV strives to encourage inefficient banks to become efficient and those with good efficiency are incentivized to continue being so. Towards this end, a transparencybased incentive method is being applied by DSGV. Different financial- and credit-based ratings (e.g. those from rating agencies such as DBRS, Fitch and Moody's) are continuously monitored and reported annually to the savings banks and their stakeholders (see dsgv.de). In this context, DSGV may want to run a more explicit incentives system coupled with an appropriate efficiency measurement mechanism which can incentivize the savings banks to a better performance. This can be done through, e.g., DEA-based incentives systems which require knowledge about the productivity change of the banks in general and their technical change and efficiency change in particular (for more details about DEA-based incentives methods see, e.g., Maziotis et al. 2016). The proposed Malmquist index can help DSGV to end up with an appropriate estimate of the benchmark technology and the results of productivity change in the way which is illustrated in the following.

\subsection{Evidence of Changes in the Savings Banks'Technology}

During the time analyzed in this study, a variety of external and internal forces - in particular resulting from financial innovations in the banking sector and the world financial crises - had an impact on the environment in which German savings banks operated. Concerning innovations as a source of changes, rapid developments in information technologies shaped the ways in which savings banks carry out their day-to-day business. Advances in internet-based communications and data processing led to financial innovations which have in turn altered savings banks' market strategies in general and their products and services in particular. For example, internet and mobile banking received great attention from customers during the time period under study. Responding to the respective changes in customer needs, German savings banks, e.g., started to collaborate with leading technology companies such as Google to provide high quality online banking services with greater convenience and flexibility (dsgv's press release No. 88 in 2012).

Another source of changes is the fact that banking is one of the most regulated industries in the world. In addition to European Central Bank, German regulators such as Bundesbank and the Federal Financial Supervisory Authority constantly monitor the market and impose certain standards, rules, regulations and restrictions on banking activities, licensing requirements, interest rate, capital requirements, deposit insurance, etc. According to the behavior of the financial market and the economic condition, these regulatory rules and restrictions often change. For example, the world financial crisis of 2007-08 revealed significant weaknesses in the regulatory and supervisory framework, both in Germany and internationally. Accordingly, regulatory contexts changed 
substantially as a consequence of the financial crisis and due to future expected risks in the financial market (for more details see, e.g., Detzer 2015).

The group of German savings banks was also affected by the financial crises and the resulting challenges arising from the regulatory conditions. They had to meet general requirements such as an increase in the minimum capital adequacy, minimum requirements for risk management and requirements for promoting the market discipline and transparency imposed from Basel II standards, which were obligatory for all financial institutions in Germany since January, 2008 (see dsgv's financial report in 2009). In addition to these requirements, the group of German savings banks had also to adapt their internal policy directives and organization strategies in the light of the financial crisis. A slowdown in the growth of funding sources of German savings banks- in terms of deposits from customers - is one example of how the financial crisis contributed negatively to their net interest income. Accordingly, and due to the low-interest rate environment afterward, savings banks strived to avoid any larger declines in income, through skilled management and - in some cases - higher commission income (see dsgv's financial report in 2013).

\subsection{Framework Specification and Data Set}

As mentioned earlier, the global Malmquist index of Kao (2010) under centralized management uses convex combinations of all observations in all time periods to estimate a single global best practice technology. Such an estimate is based on the "relaxed assumption" that the technology remains unchanged between the start and the end of the analysis. For the case of German savings banks, this forces to accept the assumption that no technical differences exist between different savings banks which are observed over the time period 2006-2012. Accordingly, we have to accept in this case that not only the external environment, such as government rules and regulations as well as the economic condition, remains unaltered over this time, but also the internal environment such as the organizational strategies, internal rules and regulations and policy directives. However, the above outlined facts reveal that this is clearly a strong premise as the banks' technology - which is naturally under the influence of different external and internal conditions - has decisively changed over time. As a consequence, including all convex combinations of all observations in all time periods in the analysis may result in an appropriate estimate of the benchmark technology.

In the following analysis, the entire period is therefore divided into shorter time periods with the length of one year. This representation is motivated by the fact that all savings banks in each time period with the length of one year can be assumed to operate under the same technology resulting from the same internal and external environment. On this basis, we accept that not only the external environment such as government rules and regulations as well as the economic condition can change over the defined periods of time, but also the internal environment which can in turn be 
affected by DSGV's preferences, i.e. organizational goals and strategies, internal rules and regulations, demands of the organization's stakeholders etc. For this case, the application of the proposed overall centralized Malmquist index seems to provide a more accurate estimate of the benchmark technology.

In order to measure productivity, input and output factors of banks' activities must be determined. Although there is no unique recommendation for selecting inputs and outputs, a number of banking behavior models have been suggested to deal with the issue. Examples are the production, intermediation, user-cost and value-added approaches (see, e.g., Ahn and Le 2014). Each of them emphasizes a specific dimension of banking activities. Hence, according to the primary goals of a bank and depending on which dimension the performance is being evaluated, a particular approach could be adopted (Ferrier and Lovell 1990). However, a literature review leads to the conclusion that researchers mainly addressed the production and intermediation approach (Berger and Humphrey 1997; Asmild et al. 2004). The former treats banks as producers of products and services such as loans and deposits using labor, fixed assets and operating expenses. In the latter, banks are considered as financial intermediaries, which collect monetary funds from savers/investors and transpose these funds into further investments to generate profit (an extensive literature review can be found, e.g., in Fethi and Pasiouras 2010; Ahn and Le 2014).

Welfare maximization is the primary objective of German savings banks. Hence, they are considered as so-called non-profit institutions which strive to increase their profit subject to their public responsibilities. In order to do so, they benefit from a dense network in all over the country which allows them to provide a wide variety of financial services for all income-level individual customers as well as SMEs within their defined geographic business areas. They also strongly support the enterprises regardless of the amount of profit the business relationship might offer. In the recession arising from the world financial crises, the financial support of German savings banks helped the SMEs to recover much faster in their industries as they were able to retain most of their employees (Simpson 2013). In addition, any request for opening an account by German citizens is not rejected by savings banks. As a result, more than half of all retail customers in Germany have their principal account with the German savings banks (Simpson 2013).

With regard to the primary goal of the German savings banks and based on the data we had access to, we specified the inputs and outputs according to the production approach. The selected inputs comprise the number of employees $\left(x_{1}\right)$, fixed assets $\left(x_{2}\right)$ and total non-interest expenses $\left(x_{3}\right)$, while the outputs are total customer deposits $\left(y_{1}\right)$ and total loans $\left(y_{2}\right)$. Descriptive statistics of the three inputs and two outputs over the time period 2006-2012, which have been extracted from the Bankscope database, are presented at the online collection as electronic supplementary material. 


\subsection{Results of the Proposed Index in Comparison with the Conventional Indices}

The standard, global and overall forms of the centralized Malmquist index and their components have been computed by solving the corresponding mathematical programming problems introduced in Sections 2 and 3 which have been encoded in AIMMS, version 3.13.

Table 1 summarizes the results, which are determined on average (calculated using a geometric mean) over the periods. The mean value of $O M I$ (i.e. the overall Malmquist index) for each of the six adjacent periods (hereafter adj-periods) is positive, signifying that productivity has been always increasing during the whole period analyzed. However, a significant reduction in the productivity improvement can be observed within the third adj-period (2008-2009), i.e. this time period encompasses the world financial crisis. Subsequently, a downward trend follows, starting from the fourth adj-period (2009-2010) to the end of the time horizon, e.g., productivity growth has fallen from $5.4 \%$ in $2009-2010$ to $0.7 \%$ in $2011-2012$. A sharp increase in the growth rate of productivity, right after the financial crises (i.e. 5.4\% in 2009-2010), reveals how the group of German savings banks was able to recover from this incident remarkably. The recovery has continued afterwards although with an obvious gradual slowdown compared to the significant progress possible right after the crises - rising back to equilibrium. The positive rates of growth highlight the fact that German savings banks had a stable financial system even when the financial crisis hit the international monetary and financial market.

Table 1. Results obtained by the centralized standard, global and overall forms of the Malmquist index.

\begin{tabular}{|c|c|c|c|c|c|c|c|c|}
\hline & 2006-07 & $2007-08$ & 2008-09 & $2009-10$ & 2010-11 & 2011-12 & $\begin{array}{l}\text { Cumulative } \\
\text { Productivity }\end{array}$ & 2006-12 \\
\hline \multicolumn{9}{|c|}{ Centralized standard Malmquist index } \\
\hline$E C$ & 1.035 & 1.060 & 0.913 & 1.091 & 1.098 & 0.836 & 1.002 & 1.002 \\
\hline$T C$ & 0.989 & 0.996 & 1.116 & 0.966 & 0.929 & 1.198 & 1.181 & 1.171 \\
\hline$M I$ & 1.023 & 1.056 & 1.019 & 1.054 & 1.019 & 1.001 & 1.184 & 1.173 \\
\hline \multicolumn{9}{|c|}{ Centralized global Malmquist index } \\
\hline$E C$ & 1.035 & 1.060 & 0.913 & 1.091 & 1.098 & 0.836 & 1.002 & 1.002 \\
\hline$B P C$ & 0.985 & 0.994 & 1.112 & 0.965 & 0.936 & 1.204 & 1.184 & 1.184 \\
\hline GMI & 1.020 & 1.053 & 1.015 & 1.053 & 1.027 & 1.006 & 1.187 & 1.187 \\
\hline \multicolumn{9}{|c|}{ Centralized overall Malmquist index } \\
\hline$E C$ & 1.035 & 1.060 & 0.913 & 1.091 & 1.098 & 0.836 & 1.002 & 1.002 \\
\hline$B P C$ & 0.982 & 0.996 & 1.112 & 0.966 & 0.936 & 1.205 & 1.186 & 1.186 \\
\hline$O M I$ & 1.017 & 1.056 & 1.016 & 1.054 & 1.027 & 1.007 & 1.188 & 1.188 \\
\hline
\end{tabular}

Circularity is often regarded as one of the fundamental properties that a productivity index and its decomposed components should obey (Førsund 2002). By definition, an index satisfies the circular test if its result computed directly between two time periods $t$ and $t+2$ is the same as the product of the results between two adjacent time periods $t$ and $t+1$ as well as between time periods $t+1$ and $t+2$. Symbolically, if an index between periods $t$ and $t+1$ is shown by $I_{t, t+1}$, the circular test 
is satisfied if $I_{t, t+1} \cdot I_{t+1, t+2}=I_{t, t+2}$. This is of particular importance in applications as it gives the possibility for comparing, e.g., the productivity of two units as observed at the same or at two different points in time without any inconsistency experienced (Portela and Thanassoulis 2008). On the other hand, the lack of this property could provide policy makers with misleading measures and directions for future decisions where, e.g., they wish to determine an appropriate estimate of the change in technology over a period of time (i.e. between 2006-2012).

The results of Table 1 provide evidence of circularity of the proposed index and its components: The cumulative productivity computed for the overall Malmquist index in 2012 is 18.8\% higher than in 2006, and $O M I$ calculated using 2006 and 2012 data generates the same value. A corresponding accordance can also be found for the global form of the Malmquist index (GMI). However, it should be noted here that this is obtained at the price of having to accept the strong assumption that there are no technical differences between banks which are observed over time (see also Section 4.5 for more detailed discussions). Furthermore, the efficiency change $(E C)$ and best practice change $(B P C)$ components in both the global and overall forms are also circular and cumulate to $0.2 \%, 18.4 \%$ and $18.6 \%$, respectively. A different picture is given by the standard Malmquist index $(M I)$ and its technical change $(T C)$ component. The cumulative productivity for $M I / T C$ in 2012 is $18.4 \% / 18.1 \%$ higher than in 2006, respectively. However, computing $M I$ and $T C$ using 2006 and 2012 data provides differences of $1.1 \%$ and $1.0 \%$, verifying that the standard Malmquist index and its technical change component are not circular and - as has been shown may produce misleading conclusions.

\subsection{Pitfalls of using the Global Malmquist Index}

As mentioned earlier in the theoretical part of the paper, in order to satisfy the circular test, the global Malmquist index of Kao (2010) implicitly assumes that the technology remains unchanged between the start and the end of the analysis. For the case of German savings banks, we have, however, provided concrete evidence in Section 4.2 that the technology has decisively changed over time. As a consequence, including all convex combinations of all observations in all time periods in the analysis (as the way the global Malmquist index applies) leads to an inappropriate estimate of the benchmark technology and accordingly to misleading results and managerial conclusions. In order to exemplify this in greater detail, 10 banks are randomly selected. Each of

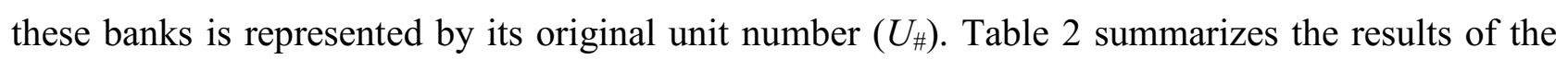
overall and global Malmquist indices shown by $O M I$ and GMI for these selected banks, respectively. 
Table 2. Results for 10 randomly selected banks by the centralized overall and global Malmquist indices.

\begin{tabular}{|c|c|c|c|c|c|c|c|c|c|}
\hline Unit & Type & 2006-07 & 2007-08 & 2008-09 & $2009-10$ & 2010-11 & 2011-12 & $B_{C M}^{8 / G}\left(U_{p}^{2007}\right)$ & $\begin{array}{l}\text { Involved } \\
\text { technology }\end{array}$ \\
\hline \multirow{2}{*}{$U_{5}$} & $O M I$ & 1.032 & 1.122 & 1.133 & 1.050 & 1.090 & 0.928 & 0.49 & 2012 \\
\hline & $G M I$ & 1.000 & 1.087 & 1.121 & 1.070 & 1.079 & 0.928 & 0.51 & 2006-12 \\
\hline \multirow{2}{*}{$U_{34}$} & $O M I$ & 1.079 & 1.102 & 0.853 & 0.995 & 1.106 & 1.071 & 0.52 & 2010 \\
\hline & $G M I$ & 1.081 & 1.142 & 0.873 & 0.999 & 1.093 & 1.073 & 0.50 & $2006-12$ \\
\hline \multirow{2}{*}{$U_{43}$} & $O M I$ & 1.119 & 1.049 & 0.924 & 1.006 & 1.047 & 1.000 & 0.57 & 2011 \\
\hline & $G M I$ & 1.248 & 1.054 & 0.932 & 1.005 & 1.030 & 1.000 & 0.65 & 2006-12 \\
\hline \multirow{2}{*}{$U_{98}$} & $O M I$ & 0.994 & 0.939 & 1.063 & 0.969 & 0.884 & 1.259 & 0.93 & 2009 \\
\hline & GMI & 1.004 & 0.974 & 1.094 & 0.970 & 0.879 & 1.258 & 0.87 & 2006-12 \\
\hline \multirow{2}{*}{$U_{114}$} & $O M I$ & 1.010 & 0.997 & 0.806 & 1.327 & 0.961 & 1.002 & 0.45 & 2012 \\
\hline & $G M I$ & 1.034 & 1.024 & 0.804 & 1.328 & 0.985 & 0.996 & 0.43 & 2006-12 \\
\hline \multirow{2}{*}{$U_{144}$} & $O M I$ & 1.037 & 0.977 & 0.981 & 1.077 & 1.026 & 1.046 & 0.55 & 2009 \\
\hline & $G M I$ & 1.025 & 1.019 & 1.017 & 1.078 & 1.030 & 1.047 & 0.51 & $2006-12$ \\
\hline \multirow{2}{*}{$U_{172}$} & $O M I$ & 1.038 & 0.996 & 1.156 & 0.973 & 1.087 & 1.060 & 0.57 & 2010 \\
\hline & GMI & 1.041 & 1.006 & 1.145 & 0.973 & 1.073 & 1.064 & 0.57 & 2006-12 \\
\hline \multirow{2}{*}{$U_{192}$} & $O M I$ & 1.184 & 0.996 & 1.046 & 1.009 & 0.708 & 1.037 & 0.65 & 2011 \\
\hline & $G M I$ & 0.959 & 1.110 & 0.995 & 1.079 & 1.005 & 1.037 & 0.52 & 2006-12 \\
\hline \multirow{2}{*}{$U_{208}$} & $O M I$ & 0.960 & 0.996 & 0.999 & 1.014 & 0.960 & 1.045 & 0.27 & 2009 \\
\hline & $G M I$ & 0.967 & 1.001 & 1.061 & 1.017 & 0.967 & 1.050 & 0.25 & 2006-12 \\
\hline \multirow{2}{*}{$U_{246}$} & $O M I$ & 1.049 & 0.976 & 0.933 & 1.005 & 0.894 & 0.996 & 0.48 & 2010 \\
\hline & $G M I$ & 1.056 & 0.991 & 0.970 & 1.007 & 0.890 & 1.000 & 0.46 & $2006-12$ \\
\hline \multirow{2}{*}{$U_{270}$} & $O M I$ & 1.183 & 1.093 & 1.089 & 1.049 & 1.009 & 1.009 & 0.68 & 2012 \\
\hline & $G M I$ & 1.087 & 1.004 & 1.023 & 1.053 & 1.025 & 0.984 & 0.77 & 2006-12 \\
\hline \multirow{2}{*}{$U_{290}$} & $O M I$ & 1.015 & 1.014 & 0.995 & 1.025 & 1.073 & 0.967 & 0.45 & 2009 \\
\hline & $G M I$ & 1.024 & 1.050 & 1.035 & 1.027 & 1.073 & 0.967 & 0.42 & 2006-12 \\
\hline \multirow{2}{*}{$U_{345}$} & $O M I$ & 1.059 & 1.007 & 1.069 & 0.934 & 1.085 & 0.995 & 0.68 & 2012 \\
\hline & $G M I$ & 1.064 & 0.984 & 1.044 & 0.943 & 1.066 & 0.996 & 0.71 & 2006-12 \\
\hline \multirow{2}{*}{$U_{377}$} & $O M I$ & 1.140 & 0.920 & 1.024 & 0.866 & 0.979 & 0.779 & 0.42 & 2007 \\
\hline & $G M I$ & 1.162 & 0.961 & 1.055 & 0.901 & 0.936 & 0.737 & 0.45 & $2006-12$ \\
\hline \multirow{2}{*}{$U_{385}$} & $O M I$ & 0.916 & 1.238 & 0.875 & 0.828 & 1.087 & 0.992 & 0.44 & 2008 \\
\hline & $G M I$ & 1.059 & 0.889 & 1.074 & 0.943 & 1.091 & 0.971 & 0.43 & $2006-12$ \\
\hline
\end{tabular}

As can be taken from Table 2, the results of the global Malmquist index differ substantially from the ones of the proposed overall Malmquist index (cf. GMI and OMI). For some banks, the productivity change values in the global form are less than those in the overall form, while the opposite is also true for some others. This can be explained by the less accurate way of aggregating the contemporaneous technologies over time in the global form of the Malmquist index. As an example, consider the overall and global Malmquist indices over the adjacent time periods 2006-07. For the determination of the $O M I$ and $G M I$ of $U_{p}$ ( $p$ : each of the above 10 selected banks), it is required to compute $B_{C M}^{8}\left(U_{p}^{2007}\right) / B_{C M}^{8}\left(U_{p}^{2006}\right)$ in the overall form and $B_{C M}^{6}\left(U_{p}^{2007}\right) / B_{C M}^{6}\left(U_{p}^{2006}\right)$ in the global form. The following comparison will be done between the nominators only (i.e. $B_{C M}^{8}\left(U_{p}^{2007}\right)$ and $\left.B_{C M}^{6}\left(U_{p}^{2007}\right)\right)$, but holds likewise between the denominators.

Note here that $B_{C M}^{8}\left(U_{p}^{2007}\right)$ and $B_{C M}^{6}\left(U_{p}^{2007}\right)$ measure the efficiencies of each selected bank using 2007 data relative to the overall and global benchmark technologies, respectively. The values of these distance functions have been reported in the second last column of Table 2 under the notation of $B_{C M}^{Q / G}\left(U_{p}^{2007}\right)$. The results provide conclusive evidence that there are considerable differences between the overall and global forms of the Malmquist index in determining the distance functions. 
This highlights the serious drawback of the global Malmquist index on the estimation of the benchmark technology and the corresponding productivity results, which may lead obviously to wrong conclusions and policy recommendations. A further diagnosis of this problem is possible by analyzing details of the involved contemporaneous technologies in forming the overall and global benchmark technologies. The respective results have been given in the last column of Table 2 .

As can be seen in the global form, all observations from all periods have been involved to construct the global technology. For example, the distance function $B_{C M}^{8}\left(U_{43}^{2007}\right)$ computes the efficiency of $U_{43}$ observed in 2007 against the global technology. Hence, the distance function has been computed by model (10) which amounts to a value of 0.65 . According to the theoretical discussion in Section 3, this model provides only a single common set of weights for measuring global distance functions of any bank observed in any period of time. Therefore, not only for this bank, but also for all other banks in different periods, this model does not distinguish between observations which are originated from different contemporaneous technologies to generate the common set of weights. In other words, observations influenced by a different internal and external environment have constructed together a single global technology to derive the common set of weights.

By contrast, the overall form of the Malmquist index is immune to this problem. The enumeration-based model in (13) guarantees an individual common set of weights for each group of observations operating under the same contemporaneous technology. For example, $B_{C M}^{Q}\left(U_{43}^{2007}\right)$ computes the efficiency of $U_{43}$ observed in 2007 against the overall technology. The value of the distance function is 0.57 which has been obtained by (13) where only observations from the same contemporaneous technology are involved in the determination of an individual common set of weights, i.e. all banks from technology 2011. This reveals that the proposed model avoids mixing observations from periods with technological differences in estimating the overall benchmark technology and accordingly determining the respective common sets of weights. This is well in line with the assumption that not only the external environment such as government rules and regulations as well as the economic condition can change over time, but also the internal environment which can in turn be affected by organizational goals and strategies, internal rules and regulations, demands of the organization's stakeholders etc.

\subsection{Further Insights Provided by the Proposed Index}

As theoretically explained in Section 3, the mathematical feature of the proposed approach of measuring the Malmquist index provides additional managerial insights which will be numerically investigated in the following. Let us focus on the intermediate results of bank $\# 43$ which were used 
to measure its overall Malmquist index reported in Table 2. According to the definition of the performance matrix in (15), these intermediate results are structured as follows:

\begin{tabular}{|c|c|c|c|c|c|c|c|}
\hline & & & & & & & \\
\hline & & 0.508 & & & 0.514 & & \\
\hline & & & & & & & \\
\hline & & & & & & & \\
\hline & & & & & & & \\
\hline & & & & & & & \\
\hline & & 0.741 & & & & & 0.000 \\
\hline & & .741 & & & & & \\
\hline
\end{tabular}

As can be seen in this matrix, there are seven rows whose values are the efficiency scores of this bank observed in period $k(k=2006, \ldots, 2012)$ according to contemporaneous technology $T^{k}$ $(k=2006, \ldots, 2012)$. For instance, in order to measure the overall Malmquist index over the time periods 2008 and 2009 , the ratio $B_{C M}^{8}\left(U_{43}^{2009}\right) / B_{C M}^{8}\left(U_{43}^{2008}\right)$ has to be computed. The problem of determining $B_{C M}^{6}\left(U_{43}^{2009}\right)$ (resp. $\left.B_{C M}^{B}\left(U_{43}^{2008}\right)\right)$ is identical with finding the minimum value among distance functions values in the fourth (resp. third) row which is 0.551 (resp. 0.596). The ratio of these two distance functions amounts to a value of productivity change of 0.924 (see Table 2). Furthermore, according to (14) for the determination of the $E C$ and $B P C$ components of the overall Malmquist index between adjacent time periods 2008 and 2009, two additional distance functions $B_{C M}^{0}{ }_{C M}^{008}\left(U_{43}^{2008}\right)$ and $B_{C M}^{8009}\left(U_{43}^{2009}\right)$ have to be determined. However, the values of these distances functions are available on the diameter of the matrix as 0.654 and 0.658 , respectively. Therefore, $E C$ and $B P C$ will be 1.006 and 0.918 , respectively. Therefore, the $E C$ component in this adj-period is $0.06 \%$, implying that the efficiency has increased from 2008 to 2009 . On the other hand, the technical change component reports a significant negative change of $8.2 \%$.

The performance of bank \#43 could also be analyzed by following other frameworks reviewed in the previous section. This can be done by, e.g., considering a vertical analysis in the matrix. For example, one can be interested in analyzing the bank's performance over the time period which contains the world financial crisis. Accordingly, the fixed-period Malmquist index given in (16) can be applied by which productivity changes between two time periods 2008 and 2009 are determined against, e.g., the contemporaneous technology 2009. This requires the ratio of two distance functions $B_{C M}^{8}{ }_{C M}^{009}\left(U_{43}^{2009}\right)$ and $B_{C M}^{8009}\left(U_{43}^{2008}\right)$ to be computed. The respective values can be found in the fourth column of the matrix as 0.658 and 0.716 , respectively. This results in 0.919 , capturing a negative change of $-8.1 \%$ in productivity. This vertical analysis refers to the Malmquist index proposed by Berg et al. (1992) with $k=2009$. The vertical perspective can straightforwardly be 
extended to also have 2008 time period in the analysis. This can either be done by the standard Malmquist index of Färe et al. (1992) given in (17) or the biennial Malmquist index of Pastor et al. (2011) in (18).

In the standard Malmquist index, the above vertical analysis has to be repeated for $k=2008$ in order to determine distance functions $B_{C M}^{8}{ }_{C M}^{008}\left(U_{43}^{2009}\right)$ and $B_{C M}^{8008}\left(U_{43}^{2008}\right)$. The values can be found in the third column of the matrix as 0.605 and 0.654 , respectively. This captures a productivity change value of $0.925(-7.5 \%$ change in productivity). With regard to (17), the geometric average of the above values of the vertical analysis is used to measure productivity change. This amounts to 0.922 which captures a decline (-7.8\%) in productivity over the time periods 2008 and 2009. Another way to include the two time periods in the analysis is forming the biennial benchmark technology $T^{B(2008,2009)}=T^{2008} \cup T^{2009}$ as a basis for measuring productivity. According to (18), the biennial Malmquist index determines the productivity change by computing the ratio of two distance functions $B_{C M}^{B(2008,2009)}\left(U_{43}^{2009}\right)$ and $B_{C M}^{B(2008,2009)}\left(U_{43}^{2008}\right)$. The respective values can be computed by the distance functions which are available from the above vertical analysis. Therefore, the biennial Malmquist is the ratio of $B_{C M}^{B(2008,2009)}\left(U_{43}^{2009}\right)=\min \{0.605,0.658\}=0.605$ and $B_{C M}^{8(2008,2009)}\left(U_{43}^{2008}\right)=\min \{0.654,0.716\}=0.654$ which amounts to 0.925 , capturing a $-7.5 \%$ change in productivity.

We may also be interested in a sequential analysis as proposed first by Shestalova (2003). In this framework, a sequential technology is formed by considering all observations in all periods up to the period under consideration, i.e. 2009. By applying the proposed pure aggregation of contemporaneous technologies, the sequential benchmark technology is formed as $T^{S(2009)}=T^{2006} \cup T^{2007} \cup T^{2008} \cup T^{2009}$. On this basis and with regard to (19), the resulting sequential Malmquist index for the unit under evaluation between two time periods 2008 and 2009 can be determined by the ratio of $B_{C M}^{\delta(2009)}\left(U_{43}^{2009}\right)$ and $B_{C M}^{\delta(2009)}\left(U_{43}^{2008}\right)$. These distance functions can be computed by (13) in which only distance functions up to period 2009 are included in the enumeration procedure. However, the required distance functions in the enumeration procedure are those which are already available in the third and fourth rows of the matrix. Therefore, they can be determined as $B_{C M}^{\delta(2009)}\left(U_{43}^{2009}\right)=\min \{0.714,0.689,0.605,0.658\}=0.605 \quad$ and $B_{C M}^{\delta(2009)}\left(U_{43}^{2008}\right)=\min \{0.742,0.703,0.654,0.716\}=0.654$. Consequently, the Malmquist index resulting from the ratio of these two distance functions leads to 0.925 , capturing a $-7.5 \%$ change in productivity. 


\subsection{Managerial Implications and Recommendations}

As has been shown in the previous sections, the detailed results based on the existing forms of the Malmquist index as compared to those determined by the proposed index are often significantly different. Considering the fact that the proposed index provides a more accurate estimate of the benchmark technology, using the numerical results of the existing forms of the Malmquist index can obviously lead to very different managerial conclusions and recommendations. Examples of the results of individual productivity changes given in Section 4.5 have verified that the choice of a productivity growth index and the implication of that choice could be very serious in terms of managerial implications, e.g., where individual performance scores are supposed to be annually reported to the banks' managers and their stakeholders for the sake of incentivisation. Taking into account these caveats, in the following we focus on the most important managerial findings drawn from our analysis. In addition to reasons behind these findings, we give recommendations for further improving the productivity of the group of German savings banks as we believe their situation can be enhanced going forward.

Details of our results reveal that the productivity of the group of German savings banks has been always increasing during the whole period analyzed. The positive rates of growth highlight the fact that German savings banks had a stable financial system even when the financial crisis hit the international monetary and financial market, i.e. although productivity remains low on average during the crises but has never deteriorated. This can be explained by the high tendency of customers to perceive German savings banks as very trustworthy, reliable and solid, especially during the crisis, whereas many other banks in the market even caused their customers to lose money. While a decline in the lending and deposit business was evident for most commercial banks, savings banks could manage to provide stable supply of loans and expand their total customer deposits throughout and after the crisis (as our data show, total customer deposits and total loans have increased over time). This is significant evidence of how the business principles of German savings banks - which are based on customer proximity and support of enterprises within their defined geographic business areas - could strengthen their position in the market.

Our results also indicate a sharp increase in the growth rate of productivity right after the financial crises, revealing how the group of German savings banks was able to recover from this incident remarkably. This recovery has continued afterwards - although with a gradual slowdown compared to the significant progress possible right after the crises. There are reasons for this slowdown. The group of German savings banks had to meet general requirements imposed from Basel II standards, which were obligatory for all financial institutions in Germany since January, 2008 (see dsgv's financial report in 2009). Therefore, they had to be focused on an increase in the 
minimum capital adequacy, in minimum requirements for risk management and in requirements for promoting the market discipline and transparency. But with the special support from their municipalities and regional offices, they astonishingly supplied significantly more new loans to SMEs and entrepreneurs, ensuring that these small and medium-sized businesses are not further impeded by the credit crunch (see dsgv's financial reports in 2009 and 2010). With this, not only could they retain their position in the German banking system but were also able to catch more attention from new costumers as they could show their high level of social responsibility, security and sustainability.

The challenge now is how the group of German savings banks can maintain its comparatively stable financial system, effective financial intermediation and low service costs while facing a high competitive environment both domestically and internationally in the market. In addition to low interest rates, which affect their deposit margin (see dsgv's financial reports in 2013 and 2014), they have to provide products to customers in the presence of rapid developments in information technologies. This growing demand for digital services was also highlighted in June 2013 by the president of DSGV who indicated that "...we are taking advantage of the opportunities available to Savings banks in the area of Web 2.0: The Internet is getting mobile, social and regional..." (see dsgv's financial report in 2012). These big challenges for German savings banks are well reflected by the numerical results presented here, as the best practice change component of the proposed overall Malmquist index verifies the significant effect of change in the technology on the performance of the German savings banks over time. Advances in internet-based communications, data processing and many other resulting financial innovations force savings banks' market strategies in general and their products and services in particular to be improved. This also provides another challenge for this group as outlined in the following.

On one hand - as also our data represent - the group of German savings banks reduced its fixed assets over time. This included a significant reduction of the number of their branches. The respective strategy is comprehensible, as services via internet and also mobile banking has received more and more attention from customers. On the other hand, this strategy seems not to be in line with the traditional business philosophy of DSGV, which has always encouraged their members to focus on the direct personal contacts with customers through a wide net of branches (see, e.g., dsgv's financial report in 2009). Nevertheless, our analysis of productivity change reveals that the group of Germany savings banks could improve even in a highly customized and growing digital business environment. This can well be explained by a closer look at the way DSGV has revised its core strategy: Its president states that "for the future, our goal is to ensure that internet users will never be more than one click away form an advisor at their local savings bank branch. This means 
that we will need to make branches future-proof and to expand our range within social networks. The scope of this development encompasses contactless payments ..., client-advisor interaction in the form of video sessions and active support in all financial matters via the web" (see, e.g., dsgv's financial report in 2012).

Unlike in the global Malmquist index, the discrete nature of the proposed overall Malmquist index in estimating the benchmark technology plays a crucial role in measuring and analyzing productivity (see Sections 3.2 and 3.3). This unique feature provides also possibilities for a further diagnosis of individual performances as already exemplified with a number of selected banks in Section 4.6. Beyond such an analysis, it allows, e.g., to identifying the highly frequented reference technologies to form the frontier of the overall benchmark technology. Our corresponding analysis of productivity change shows that the technology in 2012, followed by 2011 and 2010 technologies, contributed significantly to the shape of the overall benchmark technology. These results together with an analysis of the banks whose business strategy pays off above and below average, respectively, can provide the policy makers with additional managerial insights. Especially, successful strategy patterns can be identified and condensed to an overall business strategy for the whole savings banks group. As the three above-mentioned technologies represent the most recent experienced technological advances in the analysis, our results confirm how successful the revised strategy of the group of savings banks has been to improve their overall performance. However, looking at the slowdown in the growth of productivity between 2011-2012, it seems advisable that they should accelerate the adaptation of their business strategy, e.g. by investing more in high quality and diverse internet-based products and services to catch up with the rapid developments in information technologies.

\section{Conclusions and Outlook on Future Research}

Under the centralized management framework of Kao (2010), the global Malmquist index applies the definition by which all observations from all periods are assumed to be theoretically and potentially able to access a single global best practice technology. This benchmark technology is obtained by the convex aggregation of the experienced contemporaneous technologies. Arising from a series of practical cases, we assumed that under centralized management the external and internal environment in which DMUs operate can change over time. As a consequence, the set of common weights derived from a global benchmark technology may provide unacceptable results. In order to eliminate this pitfall, we proposed a new way of measuring the centralized global framework of the Malmquist index. The core of estimating the best practice benchmark technology 
has also been extended to other existing frameworks of the Malmquist index which apply intertemporal benchmark technology sets. Within the proposed framework, individual characteristics of the technology, represented by different contemporaneous technologies over time, can be preserved and traced later in measuring productivity change. The mathematical feature of the proposed approach also provides additional managerial outcomes for further analyzing productivity.

The proposed framework is suitable especially for situations where some variables are controlled by the central management of an organization which supervises the operating units. In such cases, an organization's higher-level managers (i.e. central decision makers) influence the organization's lower-level managers (i.e. local decision makers) in order to implement the strategies and to pursue mutual goals (Flamholtz et al. 1985; Pernot and Roodhooft 2014). However, such a centralized framework, like the one illustrated in Section 5, does not allocate all the power to make decisions that affect the future of the organization to the central decision maker. Some of this power is shared with the local decision makers who are responsible for controlling their local variables. Due of this flexibility in such a framework, it is often realized that local managers in the organization do not automatically perform actions which are imposed from above, i.e. they may focus on different business bases such as different goals and strategies which might be inconsistent with the central decision maker's preferences which are represented by, e.g., organizational goals and strategies.

Hence, the benchmarking system under centralized management typically include an appropriate set of additional controlling parameters to ensure that all processes and activities, on which local managers are in charge of, will create the desired future of the organization. These parameters, among others, can be reflected in the setting of the DEA models by, e.g., applying a set of common weights into DEA models. In such situations, the efficiency is measured on the same basis so that the decision space of the local decision makers is systematically limited. Facilitating incentive provision, a respective performance measurement system can also be applied to influence and motivate the local decision makers to decide in line with the overall strategic direction (Anthony et al. 2014). In order to exemplify how to implement the overall centralized Malmquist index in such a centralized framework, a panel of German savings banks over the time period 2006-2012 has been analyzed. The analysis has also explained reasons behind differences between the results of the proposed index and both the centralized standard and global forms of the Malmquist index.

The main objective of the paper has been to revisit the way that the inter-temporal Malmquist indices such as the global form of the Malmquist index under centralized management estimate the best benchmark technology. Therefore, the focus has always been on the structure of the proposed index under centralized management, measuring the index and then providing the highly accepted two-way decomposition of it. Future research can be concentrated on providing other 
decompositions of the proposed index. For example, the proposed index can be extended by considering another important factor, which can capture the change in scale efficiency, e.g., by following the same structure as RD decomposition in Ray and Desli (1997). In this case, since the overall technology is obtained by the aggregation of the contemporaneous technologies, the proposed index can be shown to remain immune to infeasibility for computing the corresponding components.

\section{Acknowledgement}

We gratefully acknowledge the financial support of the Deutsche Forschungsgemeinschaft (DFG) in the context of the research fund $\mathrm{AH}$ 90/5-1. We also thank the associate editor and two anonymous reviewers for their helpful remarks and suggestions.

\section{References}

Afsharian, M., H. Ahn. 2014. The overall Malmquist index: A new approach for measuring productivity changes over time. Ann. Oper. Res. 1-27.

Ahn, H., M. H. Le. 2014. An insight into the specification of the input-output set for DEA-based bank efficiency measurement. Manag. Rev. Quart. 64(1) 3-37.

Anthony, R.N., V. Govindarajan, F. G. H. Hartmann, K. Kraus, G. Nilsson. 2014. Management control systems. McGraw-Hill Higher Education, Berkshire.

Asmild, M., J. C. Paradi, V. Aggarwall, C. Schaffnit. 2004. Combining DEA window analysis with the Malmquist index approach in a study of the Canadian banking industry. J. Prod. Anal. 21(1) 67-89.

Banker, R. D., A. Charnes, W. W. Cooper. 1984. Some models for estimating technical and scale inefficiencies in data envelopment analysis. Manage. Sci. 30(9) 1078-1092.

Baums, T., M. Gruson. 1993. German banking system - System of the future. Brooklyn. J. Int. Law. 19 101-129.

Berg, S. A., F. R. Førsund, E. S. Jansen. 1992. Malmquist indexes of productivity growth during the deregulation of Norwegian banking 1980-1989. Scand. J. Econ. 94 211-228.

Berger, A. N., D. B. Humphrey. 1997. Efficiency of financial institutions: International survey and directions for future research. Eur. J. Oper. Res. 98(2) 175-212.

Charnes, A., W. W. Cooper, E. Rhodes. 1978. Measuring the efficiency of decision making units. Eur. J. Oper. Res. 2(6) 429-444.

Chen, K. H., H. Y. Yang. 2011. A cross-country comparison of productivity growth using the generalised metafrontier Malmquist productivity index: With application to banking industries in Taiwan and China. J. Prod. Anal. 35(3) 197-212.

Detzer, D. 2015. Financial market regulation in Germany: Capital requirements of financial institutions. PSL Quarterly Review. 68(272) 57-87. Available at SSRN.

Deutscher Sparkassen- und Giroverband (DSGV): Financial report. 2009.

Deutscher Sparkassen- und Giroverband (DSGV): Financial report. 2010.

Deutscher Sparkassen- und Giroverband (DSGV): Financial report. 2011. 
Deutscher Sparkassen- und Giroverband (DSGV): Financial report. 2012.

Deutscher Sparkassen- und Giroverband (DSGV): Financial report. 2013.

Deutscher Sparkassen- und Giroverband (DSGV): Financial report. 2014.

Deutscher Sparkassen- und Giroverband (DSGV): Inside the Savings Banks Finance Group. 2015. Accessed Nov 01, 2016. http://www.dsgv.de/en/facts/publications.html.

Deutscher Sparkassen- und Giroverband (DSGV): Missions and objectives. 2016. Accessed Nov 01, 2016. http://www.dsgv.de/en/about-us/index.html.

Deutscher Sparkassen- und Giroverband (DSGV): Press release Nr. 88. 2012. Accessed Nov 01, 2016. http://www.dsgv.de/de/presse/pressemitteilungen/120905_google 88.html.

Färe, R., S. Grosskopf, B. Lindgren, P. Roos. 1992. Productivity developments in Swedish pharmacies: A non-parametric Malmquist approach. J. Prod. Anal. 3 85-101.

Ferrier, G. D., C. A. K. Lovell. 1990. Measuring cost efficiency in banking: Econometric and linear programming evidence. J. Economet. 46(1) 229-245.

Fethi, M. D., F. Pasiouras. 2010. Assessing bank efficiency and performance with operational research and artificial intelligence techniques: A survey. Eur. J. Oper. Res. 204(2) 189-198.

Flamholtz, E. G., T. K. Das, A. S. Tsui. 1985. Toward an integrative framework of organizational control. Account. Org. Soc. 10 35-50.

Førsund, F. 2002. On the circularity of the Malmquist productivity index. ICER-Int. Cen. Eco. Res. No 29.

Gischer, H., P. Reichling. 2010. The German banking system and the financial crisis; in: Gup, B.E. (Hrsg.): The financial and economic crisis, Cheltenham, 69-78.

Grifell-Tatjé, E., C. A. K. Lovell. 1995. A note on the Malmquist productivity index. Econ. Lett. 47(2) 169-175.

Kao, C. 2010. Malmquist productivity index based on common-weights DEA: The case of Taiwan forests after reorganization. Omega. 38(6) 484-491.

Kao, C., H. T. Hung. 2005. Data envelopment analysis with common weights: The compromise solution approach. J. Oper. Res. Soc. 56(10) 1196-1203.

Mar-Molinero, C., D. Prior, M. M. Segovia, F. Portillo. 2014. On centralized resource utilization and its reallocation by using DEA. Ann. Oper. Res. 221(1) 273-283.

Mehrabian, S., G. R. Jahanshahloo, M. R. Alirezaee, G. R. Amin. 2000. An assurance interval for the non-Archimedean epsilon in DEA models. Oper. Res. 48(2) 344-347.

Maziotis, A., D. S. Saal, E. Thanassoulis, M. Molinos-Senante. 2016. Price-cap regulation in the English and Welsh water industry: A proposal for measuring productivity performance. Util. Policy. Article in press (doi:10.1016/j.jup.2016.04.002).

Oh, D. H. 2010. A global Malmquist-Luenberger productivity index. J. Prod. Anal. 34(3) 183-197.

Oh, D. H., J. D. Lee. 2010. A metafrontier approach for measuring Malmquist productivity index. Empir Econ. 38(1) 47-64.

Pastor, J. T., M. Asmild, C. A. K. Lovell. 2011. The biennial Malmquist productivity change index. Socio. Econ. Plan. Sci. 45(1) 10-15.

Pastor, J. T., C. A. K. Lovell. 2005. A global Malmquist productivity index. Econ. Lett. 88(2) 266271.

Pernot, E. F. Roodhooft. 2014. The Impact of inter-organizational management control systems on performance: A retrospective case study of an automotive supplier relationship. Int. J. Prod. Econ. 158 156-170. 
Portela, M. C., E. Thanassoulis. 2008. A circular Malmquist-type index for measuring productivity. Working Paper RP08-02. Aston University Birmingham B47ET, UK.

Ray, S. C., E. Desli. 1997. Productivity growth, technical progress, and efficiency change in industrialized countries: Comment. Am. Econ. Rev. 1033-1039.

Shestalova, V. 2003. Sequential Malmquist indices of productivity growth: An application to OECD industrial activities. J. Prod. Anal. 19(2-3) 211-226.

Simpson, C. V. J. 2013. The German Sparkassen (savings banks): A commentary and case study. Civitas, London.

Vitols, S. 1995. German banks and the modernization of the small firm sector: Long-term finance in comparative perspective. Discussion Paper FS I 95-309. Wissenschaftszentrum Berlin für Sozialforschung.

Wang, C. H., J. Y. Lee, Y. H. Chang. 2012. Measuring productivity in the biotechnology industry using the global Malmquist index. Appl. Econ. Lett.19(9) 807-812.

Zohrehbandian, M., A. Makui, A. Alinezhad. 2010. A compromise solution approach for finding common weights in DEA: An improvement to Kao and Hung's approach. J. Oper. Res. Soc. 61(4) 604-610. 